\title{
USE OF A FIELD-BASED WATER ELUTRIATION SYSTEM FOR MONITORING THE IN SITU PARTICLE SIZE CHARACTERISTICS OF FLUVIAL SUSPENDED SEDIMENT
}

\author{
D. E. WALLING and J. C. WoODWARD \\ Department of Geography, University of Exeter, Exeter EX44RJ, England
}

(First received August 1992; accepted in revised form March 1993)

\begin{abstract}
There is increasing evidence that a substantial proportion of the suspended sediment load transported by many rivers is composed of composite rather than primary particles. In consequence, improved techniques for determining the in situ or effective particle size characteristics of the suspended sediment and the grain size of the primary particles making up the composite particles are required in order to obtain a better understanding of both the transport and fate of such material in fluvial systems and the geochemistry of suspended particulate material. This paper describes a field-based water elutriation apparatus which has been successfully employed to investigate the in situ particle size characteristics of suspended sediment transported by the River Exe in Devon, U.K. The reported procedure allows suspended sediment to be drawn directly from the river channel and hydraulically sorted, without disturbance, into five effective size classes. In addition to providing information on the effective grain size distribution, the approach also enables the absolute grain size composition of each effective size class to be determined
\end{abstract}

Key words - fluvial suspended sediment, composite particles, particle size, water elutriation

\section{INTRODUCTION}

It is now well known that suspended particulate material plays an important role in controlling river water chemistry and that sediment-associated transport dominates the flux of many pollutants through river systems (cf. Allan, 1986; Bradford and Horowitz, 1988; Golterman et al., 1983; Walling, 1989). An improved understanding of the physical and chemical properties of such particles and of their transport through the fluvial system is therefore an important requirement for the development of water quality models and for predicting the fate of many environmental contaminants, including heavy metals, pesticides, PCBs and radionuclides (cf. Krishnappan and Ongley, 1989). Particle size probably represents the most important physical characteristic of suspended sediment, in view of its fundamental role both in controlling the transport and deposition of suspended particulate material and in influencing its capacity to adsorb contaminants (cf. Horowitz, 1991). A knowledge of the particle size characteristics of fluvial suspended sediment is therefore an essential prerequisite for many environmental investigations.

Recent research over the past two decades has drawn increasing attention to the importance of composite particles, as distinct from discrete primary particles, in accounting for the suspended particulate material in many aquatic environments, including estuaries (e.g. Biddle and Miles, 1972; Zabawa, 1978; Eisma et al., 1980; Bale and Morris, 1987), lakes (e.g. Duck, 1986) and rivers (e.g. Walling and Moorehead,
1989; Droppo and Ongley, 1989, 1992). Composite particles, which are often referred to as aggregates or flocs, are frequently an order of magnitude or more larger in size than their constituent particles and their ubiquity in aquatic environments has important implications for both the hydrodynamic behaviour of suspended particles (cf. Kranck, 1975; Chase, 1979; Krishnappan and Ongley, 1989) and the interrelationship between the size and geochemistry of such particles (cf. Umlauf and Bierl, 1987). In many instances the mineralogy, chemical composition and contaminant loading of composite particles of a given size will differ substantially from that of primary particles of equivalent size.

Although uncertainties still exist regarding the precise mechanisms responsible for the formation of composite particles, recognition of their existence necessitates acceptance of the important distinction between the in situ or effective particle size distribution of suspended particulate material, which reflects the presence of composite particles, and the absolute or ultimate grain size distribution obtained after particle disaggregation and chemical dispersion, which reflects the grain size of the primary particles. To date, however, progress in this direction has been slow, because of the difficulties involved in obtaining in situ measurements of the size of composite particles and in collecting particles representative of different effective size classes. The latter is important to provide information regarding the size of the primary particles making up composite particles of a particular size class and to determine the geochemistry of 
specific effective size classes. Within the fluvial environment, relatively few researchers have either recognized the need, or developed viable techniques, to obtain information on the effective size properties of suspended sediment. Droppo and Ongley (1989, 1992) report the use of small perspex settling tubes to collect suspended particles on inverted microscope slides for direct measurement of the size of individual particles using digitizing techniques. An alternative approach, based on estimation of in situ settling velocities and involving the use of a modified Owen tube or bottom withdrawal tube sampler (cf. Owen, 1976), was employed by Walling and Moorehead (1989). The further development of these and other approaches capable of providing information on both the ir situ particle size characteristics of fluvial suspended sediment and the grain size of the primary particles comprising composite particles, must undoubtedly be seen as an important research need.
This paper presents some findings of a study currently being undertaken in the River Exe basin in Devon, U.K. (Fig. 1), where a number of complementary approaches to investigating the in situ particle size characteristics of fluvial suspended sediment and the nature and composition of composite particles are currently under development. As part of this programme we have evaluated a new application of a water elutriation apparatus which permits suspended sediment to be withdrawn directly from the river channel and hydraulically sorted, without disturbance, into five predetermined effective grain size classes. In addition, the approach also permits the determination of the absolute size characteristics of the mineral fraction of each effective size class in a reliable and consistent manner. Thus we can determine not only the relative contribution of each effective size class to the overall suspended sediment load of a river, but also the size range of the mineral

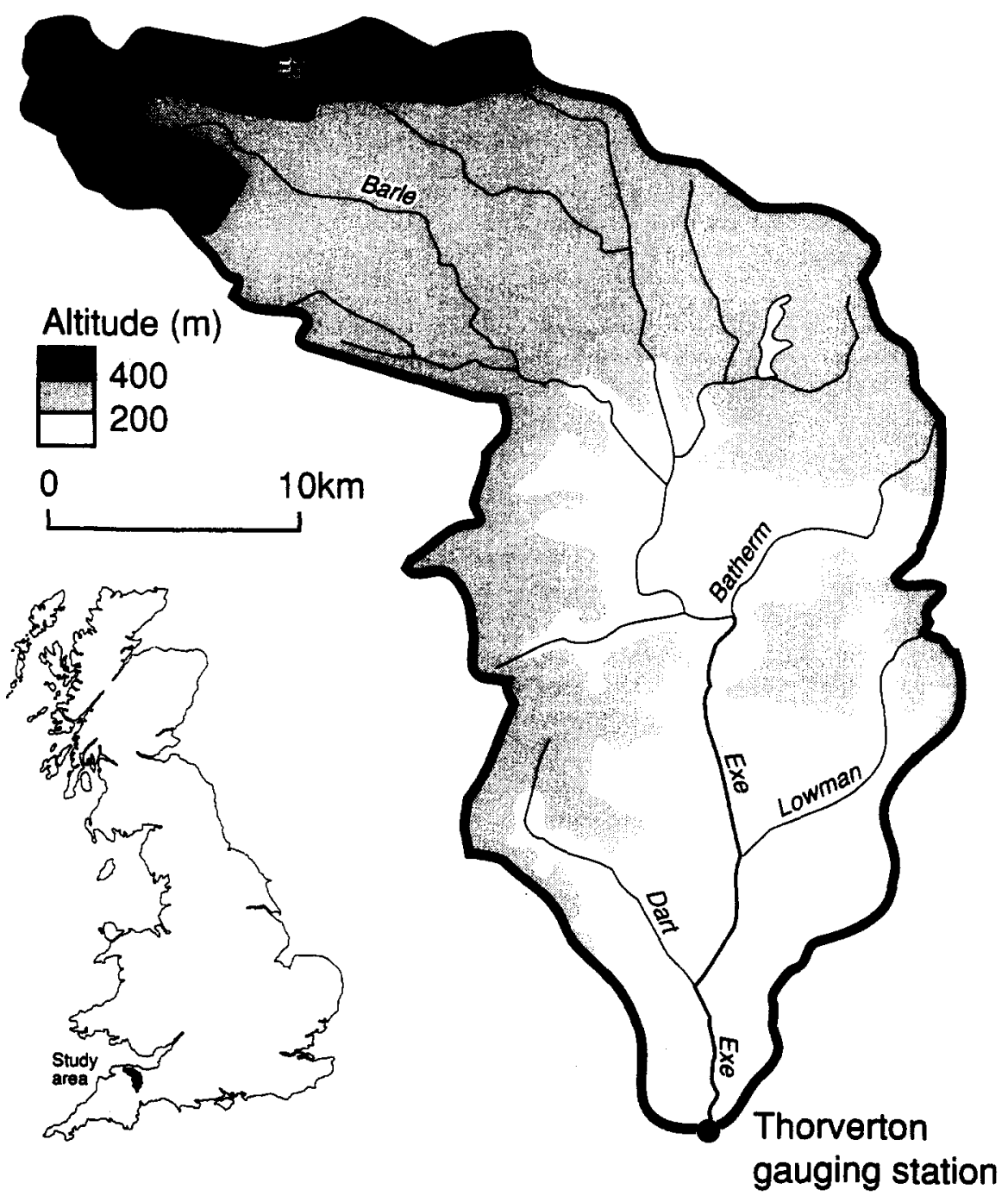

Fig. 1. Location map showing the drainage basin of the River Exe upstream of the suspended sediment sampling site at Thorverton gauging station. 


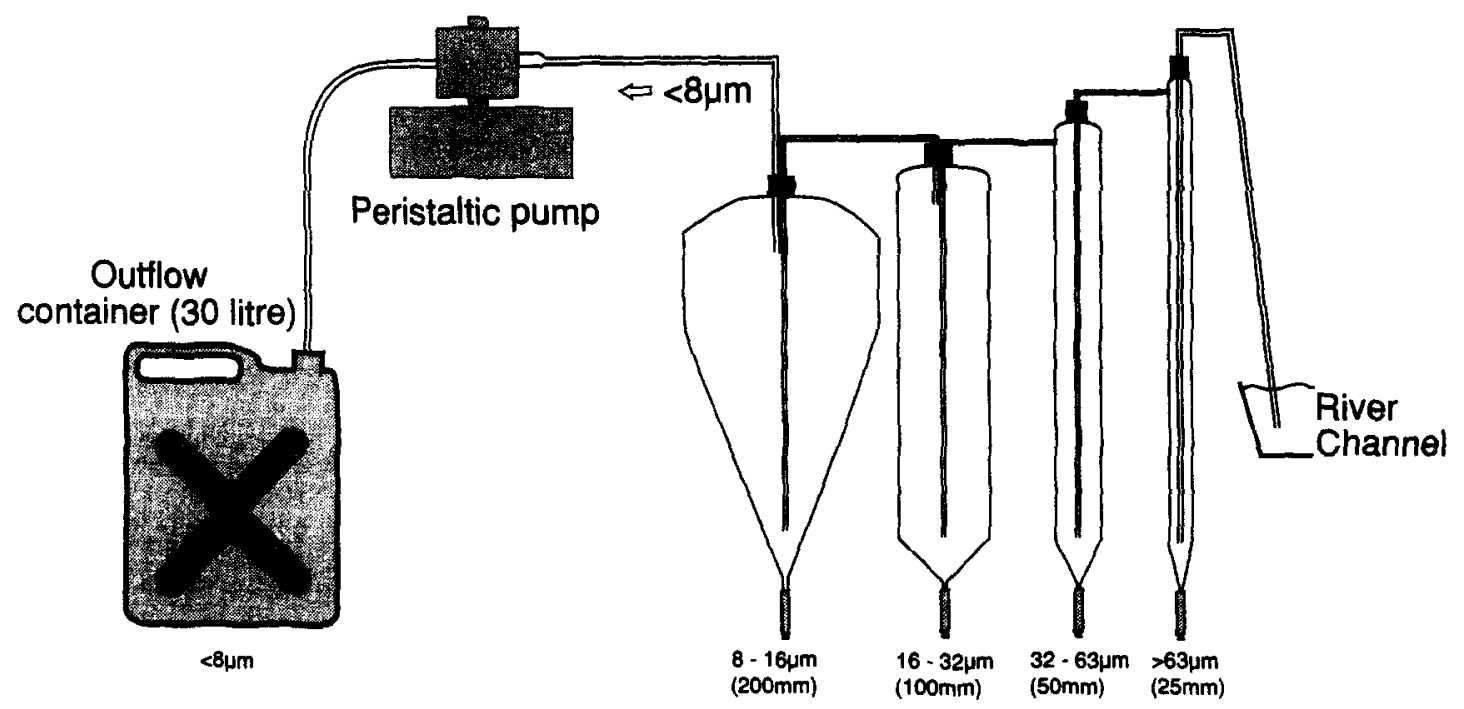

Fig. 2. The water elutriation apparatus described in this paper. The internal diameters of the cylindrical portion of each sedimentation chamber are shown in parentheses.

particles comprising each effective class and therefore the relative importance of primary and composite particles within that class. The simplicity of the water elutriation procedure means that it can be deployed at field monitoring sites as a means of sampling and fractionating fluvial suspended sediment under essentially in situ conditions.

\section{THE WATER ELUTRIATION APPARATUS AND ITS FIELD DEPLOYMENT}

\section{The apparatus}

The custom-built water elutriation apparatus used in this study is illustrated in Fig. 2. It consists of four glass sedimentation chambers linked by glass and flexible PVC tubing (4 $\mathrm{mm}$ i.d.); a peristaltic pump with variable speed control; and a $30 \mathrm{l}$. capacity outflow container. The cylindrical portions of the sedimentation chambers have internal diameters of $25,50,100$ and $200 \mathrm{~mm}$, respectively. The sampling inflow to the system is provided by a length of plastic tube $(4 \mathrm{~mm}$ i.d.) connected to the first $(25 \mathrm{~mm})$ sedimentation chamber. The peristaltic pump is able to maintain a constant flow rate throughout the sampling period and is positioned in-line after the $200 \mathrm{~mm}$ sedimentation chamber, to ensure that the structure of the sediment particles passing through the system is not influenced by the mechanical action of the pump and that they pass in essentially their in situ form through the four sedimentation chambers. The outflow from the pump is collected in the $30 \mathrm{I}$. container.

\section{The principle of operation}

The principle of water elutriation and its application to the fractionation of fine-grained sediment has been documented by several workers and the validity of the results obtained has been verified through comparison with the pipette and Coulter Counter methods (e.g. Beavers and Jones, 1966; Follmer and Beavers, 1973; Muller and Tisue, 1977). While all of these studies involved laboratory-based fractionation of chemically-dispersed sediment, a more recent application reported by Umlauf and Bierl (1987) has demonstrated that water elutriation can also be applied successfully to the fractionation of natural suspended particulate material under field conditions.
In essence, water elutriation sorts suspended sediment particles into a number of size classes by passing the water/sediment mixture through a series of successively larger sedimentation chambers, which provide a sequential reduction in flow velocity. Particles enter in suspension at the base of each chamber via a "long" glass tube and may exit via a "short" tube at the top of the chamber (Fig. 2). Sediment particles that settle at velocities greater than the upward velocity of the flow remain within the chamber, while those that settle at lower velocities are carried upwards and into the next chamber. The turbulence generated at the base of each sedimentation chamber promotes effective sorting of the suspended particles, since the finer material is carried upwards into the zone of laminar flow within the upper section of the chamber.

The dimensions of the apparatus shown in Fig. 2 take advantage of the fact that doubling the diameter of the sedimentation chambers (i.e. from 25-50 to $100-200 \mathrm{~mm}$ ) causes their cross-sectional area to be increased by a factor of four. To obtain the desired (critical) particle sizes, the velocity of the flow in successive chambers must decrease by a proportion determined by Stokes' law:

$$
V=k r^{2}
$$

where $V$ is the velocity of a settling particle, $k$ is the proportionality constant and $r$ is the radius of the particle (Follmer and Beavers, 1973, p. 546). Thus doubling the diameter of the sedimentation chamber, for a given flow of water, halves the minimum size of particle that will be retained in successively larger chambers (Beavers and Jones, 1966). The flow rate through our apparatus is adjusted according to ambient water temperature to retain particles with equivalent spherical diameters (assuming a density of $2.65 \mathrm{~g} \mathrm{~cm}^{-3}$ ) of $>63,63-32,32-16$ and $16-8 \mu \mathrm{m}$ in the four glass sedimentation chambers. Suspended sediment particles within these size classes are deposited at the base of each chamber and are collected in short $(c .15 \mathrm{~cm})$ lengths of transparent rubber tubing sealed with rubber bungs (Fig. 2). This simple "tap" mechanism has proved more effective and less expensive than the ground glass taps employed by other investigators and allows all the deposited sediment to be recovered. The $<8 \mu \mathrm{m}$ fraction is collected by retaining the outflow of the system. At the end of a run, clear water must be drawn through the sedimentation chambers to ensure that all the particles present in the system are allowed to 
reach the sedimentation chamber appropriate to their size. The elutriation procedure is complete when the sedimentation chambers have been completely flushed with clear water. The sediment is then carefully washed from each chamber into plastic bottles. The outflow collector, which contains the $<8 \mu \mathrm{m}$ fraction, is also retained.

\section{Field deployment}

For field deployment, the apparatus shown in Fig. 2 was housed in a wooden shelter located close to the river bank and the $4 \mathrm{~mm}$ i.d. intake tube was fixed to a permanent stake in the river channel at a level below the minimum water stage. Because it is important to ensure that the suspended sediment concentrations in the river water entering the apparatus are representative of those within the river channel, a number of tests aimed at comparing the suspended sediment concentrations of samples pumped through the inlet tube with those collected using a standard US DH48 depth integrating suspended sediment sampler (cf. Vanoni, 1975) were undertaken. These tests demonstrated close agreement between the two types of sample. The lack of any significant difference between the two methods of sample collection is thought to reflect the relatively fine nature of the suspended sediment transported by the River Exe (cf. Walling and Moorehead, 1989). Clay- and silt-sized particles dominate the absolute grain size distribution of the suspended sediment load of this river and the sand fraction rarely exceeds $4 \%$ of the total load. Flow velocities within the intake tube were sufficient to transport particles in excess of c. $250 \mu \mathrm{m}$ and the lack of a significant sand fraction means that suspended sediment concentrations within the channel cross section will be relatively constant (cf. Culbertson, 1977). In rivers where the sand fraction represents a substantial proportion of the total suspended sediment load, ensuring that suspended sediment entering the apparatus is representative of that transported by the river may be more problematical. In such situations, concentrations will vary in the cross section and the suspended sediment concentration of a sample withdrawn from a single point will not be representative of the overall section. Furthermore, a simple intake tube, orientated normal to the flow is unlikely to provide the isokinetic sampling conditions which are necessary to ensure that the concentrations in the sample are representative of those at the point of withdrawal.

Since the object of using the water elutriation apparatus is to examine the effective particle size distribution of the suspended sediment transported by the river and to collect samples of the individual effective size classes, it is also important to consider if the composite particles passing into and through the apparatus are representative of those in the river. Such information is difficult to obtain (cf. Droppo and Ongley, 1992), but the features of the apparatus are such that laminar flow exists within the central and upper portions of each chamber (cf. Beavers and Jones, 1966). Turbulence occurs at the base of the inlet tube but since this was no greater than that occurring naturally in the river, it was therefore judged unlikely that significant break-up of composite particles would occur. The water elutriation apparatus described above was operated during storm runoff events when suspended sediment concentrations in the river exceeded $100 \mathrm{mg} 1^{-1}$. The availability of a continuous turbidity monitor assisted greatly in defining such periods. Water was drawn from the river into the apparatus for periods of up to $8 \mathrm{~h}$ during individual sampling runs. The results obtained therefore represent a time-integrated measure of the effective particle-size distribution of the transported sediment. The length of the sampling period varied according to the magnitude and duration of the runoff event and the associated suspended sediment concentrations.

When initiating a sampling run the apparatus must be filled with clear water, the temperature and chemical prop- erties of which are as close as possible to those of the ambient river water. In this study filtered river water was used. As sediment-laden river water is drawn from the river into the apparatus, a distinct sediment "plume" can be observed which effectively traces the passage of native river water through the system and allows direct examination of flow conditions within the sedimentation chambers during sample runs. No turbulence has been observed in the cylindrical portions of the elutriation system (cf. Beavers and Jones, 1966). All the sediment particles entering the apparatus behind the sediment plume settle out in native river water and are therefore not subjected to any changes in water chemistry during the fractionation process. Towards the end of a sampling run, when either an entire event or a representative portion of an event has been sampled, and at least one of the collecting tubes at the base of the sedimentation chambers is approaching capacity, clear water is drawn through the system. Clear water may be drawn directly from the stream channel if the river water becomes clear at the end of a runoff event, or, alternatively, it can be drawn from a container containing water with properties similar to those of the native river water.

\section{Sample processing}

The sediment samples collected from each sedimentation chamber are centrifuged to remove excess water and then frozen and freeze dried. The sediment collected in the outflow container(s) is left to settle for at least $72 \mathrm{~h}$ and is then decanted, centrifuged, frozen and freeze dried. The total amount of sediment associated with each of the five effective size classes is then determined by weighing. These samples are subsequently treated with hydrogen peroxide to remove the organic fraction and chemically dispersed following standard laboratory procedures (cf. McManus 1988). The absolute particle size distribution of the mineral sediment comprising each effective class was measured using a Malvern MasterSizer laser diffraction particle size analyser.

\section{RESULTS}

The information on the weight of sediment associated with each of the five effective size classes provided by the water elutriation apparatus can be used to derive a simple group frequency distribution which represents the effective particle size distribution of the sampled sediment. As noted above the effective size classes were defined using Stokes' law, assuming a particle density of $2.65 \mathrm{~g} \mathrm{~cm}^{-3}$. It is to be expected that the density of many composite particles, particularly those containing a significant organic component, will be less than this value. Thus defined, the size classes may underestimate the actual size of the composite particles, but they will directly reflect their hydraulic behaviour or "hydraulic size" in the stream. The distributions for five storm runoff events sampled from the River Exe at Thorverton (Fig. 1) are presented in Fig. 3. These events occurred between October 1991 and April 1992 and are characterized by only limited inter-event variation in the form of the distribution. Figure 3 indicates that the greatest inter-event variability is associated with the $<8 \mu \mathrm{m}$ class, which accounts for between 18.2 (21/12/91) and $33.7 \%(12 / 03 / 92)$ of the overall load, with a mean value of $24.9 \%$ for the five events sampled. The distributions are dominated by the $<8$, 16-32 and $32-63 \mu \mathrm{m}$ classes which in turn demon- 
strates both a relative paucity of primary particles in the 8-16 $\mu \mathrm{m}$ range and that composite particles commonly exceed this size. While it is likely that both these factors are important, this feature is accentuated by cumulating all finer material in the $<8 \mu \mathrm{m}$ class.

The absolute size distributions of the mineral sediment associated with each of the effective size classes fractionated by the elutriation apparatus have been determined and Fig. 4 presents the results for the event of $31 / 10 / 91$. In comparing the absolute size distribution of the sediment representing a particular effective class with the size range of that class, it is important to recognize that the water elutriation results represent equivalent spherical diameters derived using Stokes' law of settling coupled with assumptions concerning particle density, whereas the MasterSizer results involve direct optical sizing by laser diffraction and represent only the mineral fraction of the sediment contained within each effective class. The results are, therefore, not directly compatible, but some comparisons are, nevertheless, possible. The mineral fraction of the sample collected during the event of $31 / 10 / 91$ accounts for approx. $93.5 \%$ of the total suspended sediment load and it is therefore not unreasonable to assume that the absolute grain size distributions derived for the mineral fraction are representative of the overall suspended sediment load. Figure 4 indicates that all of the effective classes $>8 \mu \mathrm{m}$ contain significant proportions of clay-sized $(<2 \mu \mathrm{m})$ particles. This material must have been contained within larger composite particles, since the water elutriation process has been shown to be particularly efficient at separating discrete fine particles from a sediment sample (cf. Muller and Tisue, 1977).

Using data of the type represented in Fig. 4 and information on the proportions of the total load associated with each of the five effective size classes, it is possible to synthesize the absolute particle size

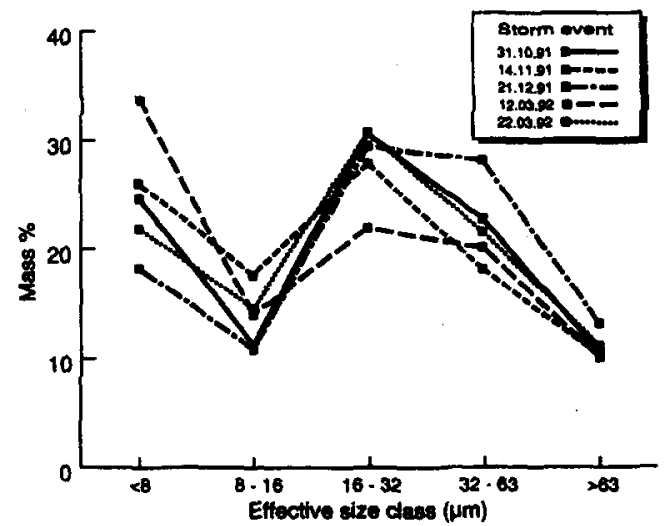

Fig. 3. Total mass of suspended sediment in each effective size class for five storm runoff events in the River Exe basin. These events were sampled at Thorverton between October 1991 and April 1992.

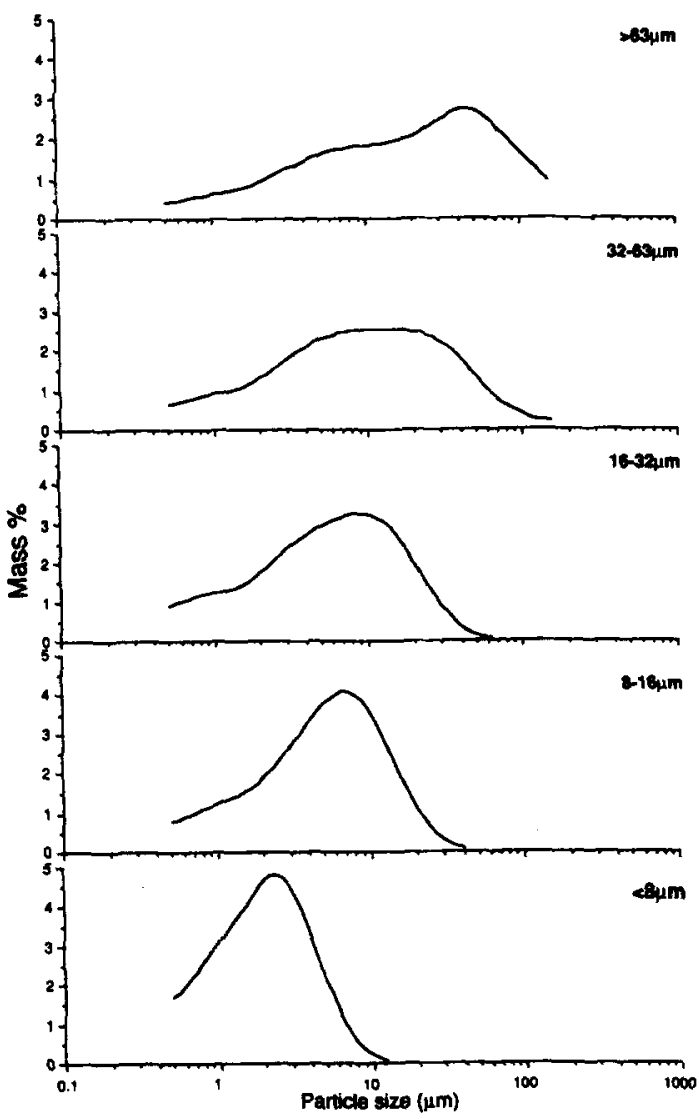

Fig. 4. Typical absolute size distributions obtained for each of the effective classes fractionated by the elutriation apparatus. These samples were collected during the flood event on $31 / 10 / 91$ and the distributions represent the chemically dispersed mineral fraction.

distribution of the total suspended load at the time of sampling. Figure 5 presents a comparison of the effective group frequency size distribution with an equivalent representation of the absolute particle size distribution synthesized in this manner for the event of $31 / 10 / 91$. This comparison emphasizes the potential contrast between the two distributions. In this case the median grain size of the absolute distribution falls within the $<8 \mu \mathrm{m}$ class whereas that for the effective distribution is of the order of $S$ times greater and falls within the $16-32 \mu \mathrm{m}$ class. The proportion of the total load contributed by the $>63 \mu \mathrm{m}$ class can also be seen to be significantly greater for the effective size distribution (10.55\%) than for the absolute size distribution (3.23\%). This is in good agreement with previous estimates of the contribution to the absolute size distribution of sediment particles $>63 \mu \mathrm{m}$ in size reported by Lambert and Walling (1988). This study demonstrated that the sand content of a large number of bulk suspended sediment samples collected over a range of flow conditions from the Thorverton station averaged $3.8 \%$. This in turn indicates that the in situ suspended sediment load includes a substantial num. ber of composite particles $>63 \mu \mathrm{m}$ in size as well as 
discrete particles in the fine sand size range. This is consistent with recent studies undertaken by the authors involving SEM analysis of individual composite particles which have demonstrated that composite particles up to $200 \mu \mathrm{m}$ may be present in the suspended sediment load of the River Exe (cf. Woodward and Walling, 1992).

Information on the absolute particle size distributions associated with each effective size class may also be used to calculate the proportion of clay-sized $(<2 \mu \mathrm{m})$ material incorporated within each effective class [Fig. 6(A)]. In this river, each of these effective size classes contains a substantial proportion of $<2 \mu \mathrm{m}$ material. By combining these data with those presented in Fig. 3 it is possible to calculate the proportion of the total transport of clay-sized particles associated with each effective size class. These results, presented in Fig. 6(B), indicate that in this river the effective size classes covering the range $>8 \mu \mathrm{m}$ account for $>40 \%$ of the total load of clay-sized particles.

Although the results provided by the water elutriation apparatus do not permit direct evaluation of the proportion of particles within an effective size class existing as either composite or discrete primary particles, it is possible to generate some estimates of these proportions using the results presented above. If the absolute particle size distribution of the sediment associated with a particular effective size class is compared with the lower size limit of that effective
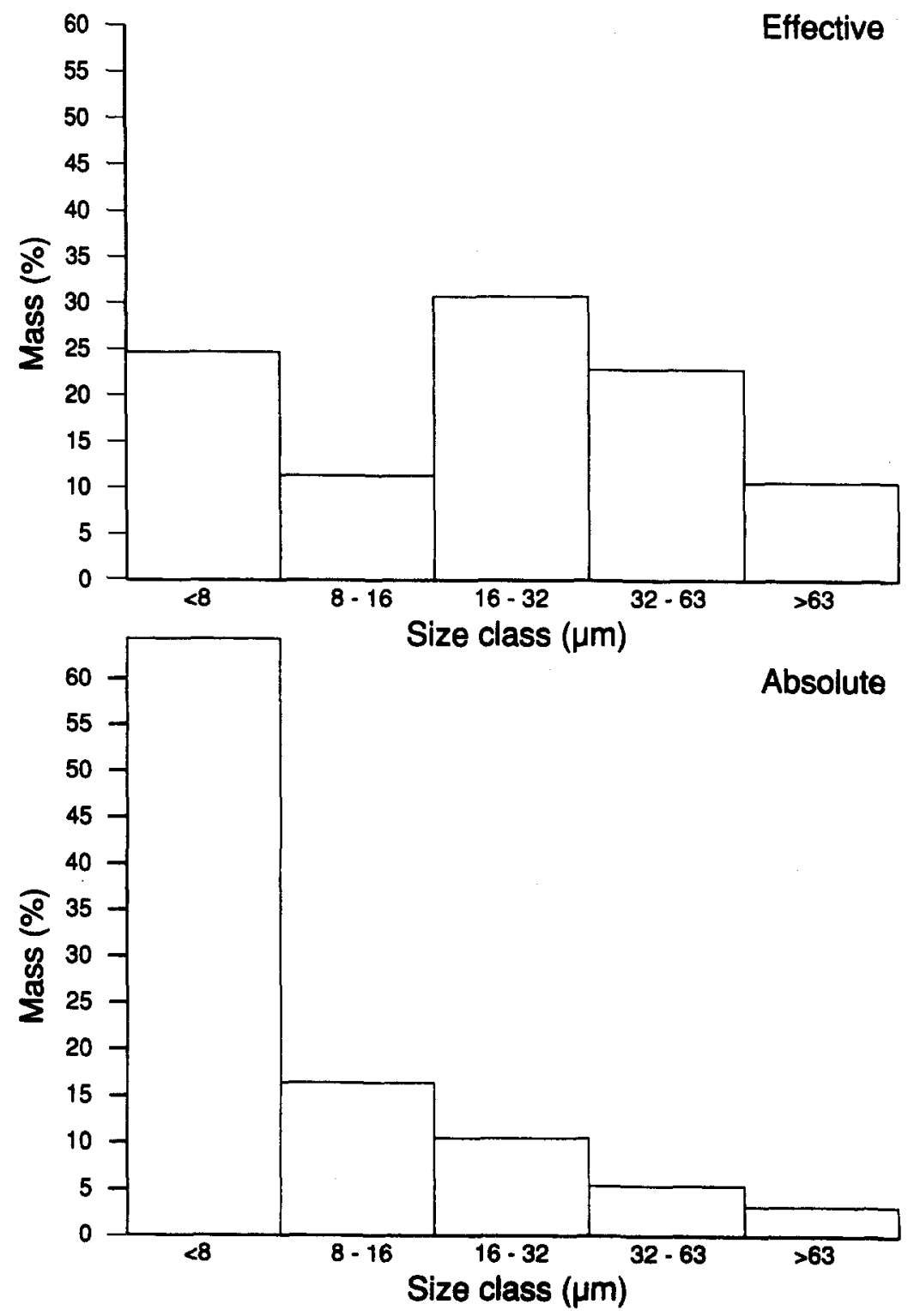

Fig. 5. A comparison of the absolute and effective size distributions for suspended sediment collected during the storm event of $31 / 10 / 91$. 

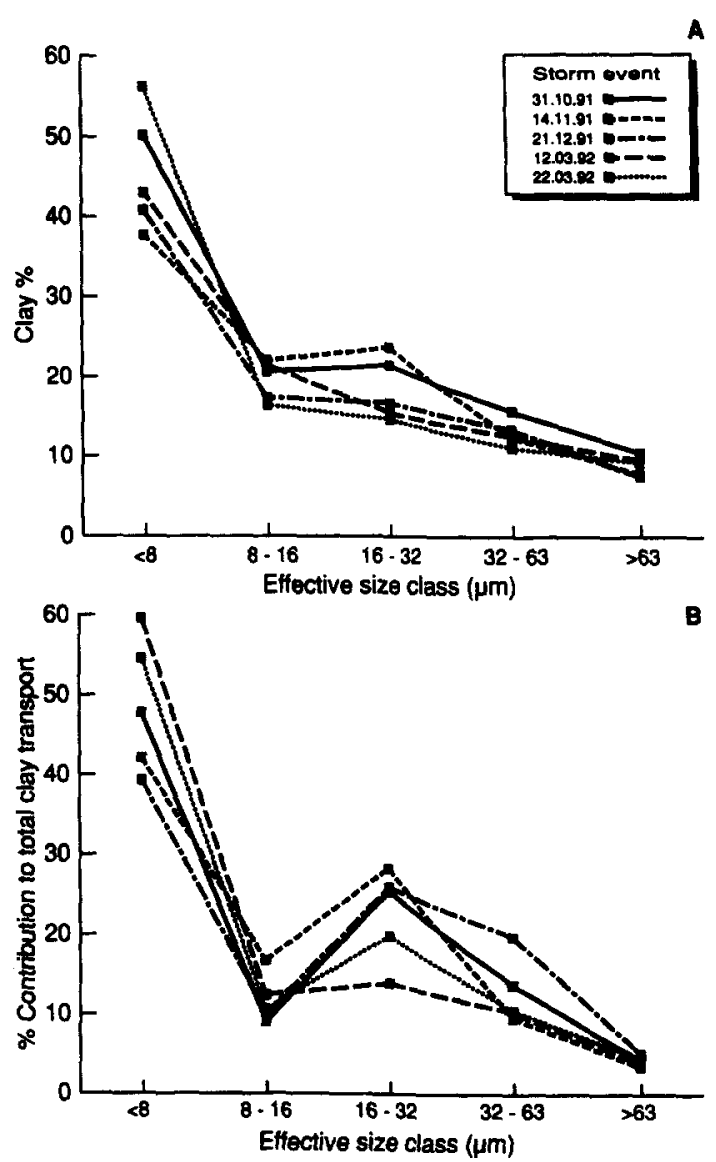

Fig. 6. (A) The proportion of clay-grade $(<2 \mu \mathrm{m})$ particles in each effective class for the five storm discharge events shown in Fig. 3. (B) The proportion of clay in each of the effective size classes expressed as a percentage of the total amount of clay transported during each sampling period.

class and the proportion of the total mass of the dispersed sediment falling below this limit is calculated, this value provides an estimate of the proportion of sediment within that effective size class incorporated into composite particles. Primary particles of a size less than the lower class limit should only be represented in the sediment associated with an effective class if they were incorporated into composite particles. This estimate of the proportion of the sediment within an effective class which is incorporated into composite particles is, in fact, likely to be an underestimate, in that it cannot be assumed that the entire portion of the absolute size distribution representing sediment of a size greater than the lower limit of the effective class existed as primary particles under in situ conditions. The estimate also only applies to the mineral fraction of the sediment, but since this represents $c .90 \%$ of its original mass in the case of this river, any error involved in extrapolating to the total sediment mass associated with a specific effective class is likely to be minimal, particularly because much of the organic fraction is likely to be incorporated into composite particles. Table 1 pre- sents estimates of the proportions of four out of the five effective size fractions collected using the water elutriation apparatus during the storm runoff event of $31 / 10 / 91$ which existed as composite particles. It is not possible to provide an equivalent estimate for the $<8 \mu \mathrm{m}$ effective class, although the proportion is not likely to differ substantially from that for the other four classes. These results indicate that composite particles account for a very substantial proportion of the suspended sediment load of the River Exe.

\section{DISCUSSION}

The results presented above demonstrate that the water elutriation apparatus employed by the authors affords a useful means of assembling information concerning the in situ particle size distribution of fluvial suspended sediment and the importance and grain size composition of associated composite particles. Because the river water entering the elutriation apparatus passes essentially undisturbed from the river into the sedimentation chambers, the results provided by the apparatus are thought to provide a meaningful representation of the effective particle size characteristics of the suspended sediment transported by the river. The possibility that some aggregation of particles occurs within the delivery tubes and sedimentation chambers, for example by particle collision, must, however, be recognized. This mechanism is thought not to be of major significance, in view of the relatively low sediment concentrations involved $\left(<500 \mathrm{mg} \mathrm{l}^{-1}\right.$ ). However, as a means of providing some degree of independent verification of the information provided by the water elutriation apparatus, the results obtained for the storm runoff event on $12 / 03 / 92$ were compared with equivalent measurements of the effective particle size characteristics of the suspended sediment obtained using a Valeport SK 110 water/sediment sampler which can be viewed as a modified Owen tube. In this device, the sampling tube, which is lowered horizontally into the river, doubles as a sedimentation column. The sample is trapped by closing the ends of the tube and the tube is then removed from the river and inverted into a vertical position to serve as a bottom withdrawal tube (cf. Owen, 1976). The results presented in Table 2 indicate that the results produced by the two approaches are in close agreement. Some differences must be expected since the results provided by the Valeport sampler represent a single instantaneous

Table 1. Amount of dispersed mineral material (\%) in each effective size class finer than the lower size limil of that effective size class. These data provide an estimate of the proportion of sediment incorporated into composite particles within the four coarsest effective size classes. Data refer to the event of $31 / 10 / 91$

\begin{tabular}{cccc}
\hline & \multicolumn{2}{c}{ Effective size class $(\mu \mathrm{m})$} \\
$8-16$ & $16-32$ & $32-63$ & $>63$ \\
\hline 68 & 85 & 83 & 80.5 \\
\hline
\end{tabular}


Table 2. A comparison of effective size data derived from the water elutriation apparatus with effecrive size data obtained using the Valeport SK110 water sediment sampler as a bottom withdrawal tube. Both data sets (in mass \%) refer to sumples collected during the same storm event at Thorverton on 12/03/92

\begin{tabular}{lccccc}
\hline & \multicolumn{5}{c}{ Effective size class $(\mu \mathrm{m})$} \\
Method & $<8$ & $8-16$ & $16-32$ & $32-63$ & $>63$ \\
\hline Elutriation & 33.7 & 14.1 & 22.0 & 20.1 & 10.10 \\
BWT & 42.0 & 10.0 & 17.5 & 22.0 & 8.50 \\
\hline
\end{tabular}

sample collected from the river, whereas those generated by the water elutriation apparatus represent a time-integrated sample collected over a period of several hours. The water elutriation apparatus possesses a major advantage over the Owen tube type of sampler in that it enables the absolute particle size distribution associated with the individual effective size classes to be determined and information on the relative importance of composite particles to be derived.

The results provided by the water elutriation apparatus for the River Exe at Thorverton underscore the importance of recognizing the distinction between the absolute and effective particle size distributions of fluvial suspended sediment. The median grain size associated with the former distribution is $<8 \mu \mathrm{m}$, whereas that of the latter lies within the $16-32 \mu \mathrm{m}$ effective size class. Figure 5 also indicates that whereas only $c .35 \%$ of the primary particles exceed $8 \mu \mathrm{m}$ in diameter, more than $75 \%$ of the in situ suspended sediment particles exceed this size. This clear contrast between the absolute and effective grain size distributions has important implications for the dynamics of suspended sediment transport and deposition within the river system. Use of the potential afforded by the water elutriation apparatus for investigating the primary particle composition of a number of effective size classes has also demonstrated that composite particles dominate the total suspended sediment load of the River Exe and that in excess of $50 \%$ of the clay-sized $(<2 \mu \mathrm{m})$ material transported is incorporated into much larger $(>8 \mu \mathrm{m})$ composite particles. This in turn has important implications both for the fate of contaminants and other substances that are preferentially associated with the clay fraction and for the geochemical properties of the composite particles. These findings further highlight the important need for equipment, such as the water elutriation apparatus described in this paper, which is capable of providing information on the in situ particle size characteristics of fluvial suspended sediment.

Acknowledgements - The financial support provided by the U.K. Natural Environment Research Council for the work reported in this paper and the cooperation of the National Rivers Authority in permitting access to the flow gauging station on the River Exe at Thorverton are gratefully acknowledged.

\section{REFERENCES}

Allan R. J. (1986) The role of particulate matter in the fate of contaminants in aquatic ecosystems. Inland Waters Directorate (Canada) Scientific Series No. 142.

Bale A. J. and Morris A. W. (1987) In situ measurement of particle size in estuarine waters. Estuar. Coast. Shelf Sci. 24, 253-263.

Beavers A. H. and Jones R. L. (1966) Elutriation for fractionating silt. Soil Sci. Soc. Am. Proc. 30, 126-128.

Biddle P. and Miles J. H. (1972) The nature of contemporary silts in British estuaries. Sediment. Geol. 7, 23-33.

Bradford W. L. and Horowitz A. J. (1988) The role of sediments in the chemistry of aquatic systems. U.S. Geological Survey Circular No. 969.

Chase R. R. P. (1979) Settling behaviour of natural aquatic particulates. Limnol. Oceanogr. 24, 417-426.

Culbertson J. C. (1977) Influence of flow characteristics on sediment transport with emphasis on grain size and mineralogy. In The Fluvial Transport of Sediment-associated Nutrients and Contaminants (Edited by Shear H. and Watson A. E. P.), pp. 117-133. International Joint Commission, Windsor, Ontario.

Droppo I. G. and Ongley E. D. (1989) Flocculation of suspended solids in Southern Ontario rivers. In Sediment and the Environment (Edited by Hadley R. J. and Ongley E. D.), IAHS Publ. No. 184, pp. 95-103. IAHS, Wallingford.

Droppo I. G. and Ongley E. D. (1992) The state of suspended sediment in the freshwater fluvial environment: a method of analysis. Wat. Res. 26, 65-72.

Duck R. W. (1986) Aspects of physical processes of sedimentation in Loch Earn, Scotland In International Geomorphology (Edited by Gardiner V.), Part 1, pp. 801-821. Wiley, Chichester.

Eisma D. J., Kalf J. and Veenhuis M. (1980) The formation of small particles and aggregates in the Rhine estuary. Netherl. J. Sea Res. 14, 172-191.

Follmer L. R. and Beavers A. H. (1973) An elutriation method for particle size analysis with quantitative silt fractionation. J. Sediment. Petrol. 43, 544-549.

Golterman H. L., Sly P. G. and Thomas R. L. (1983) Study of the relationship between water quality and sediment. UNESCO Technical Papers in Hydrology, No. 26 UNESCO, Paris.

Horowitz A. J. (1991) A Primer on Sediment Trace-element Chemistry, 2nd edition. Lewis, Mich.

Kranck K. (1975) Sediment deposition from flocculated suspensions. Sedimentology 22, 111-123.

Krishnappen B. G. and Ongley E. D. (1989) River sediment and contaminant transport-changing needs in research. In Proceedings of the Fourth International Symposium on River Sedimentation, pp. 530-538.

Lambert C. P. and Walling D. E. (1988) Measurement of channel storage of suspended sediment in a gravel-bed river. Catena 15, 65-80.

McManus J. (1988) Grain size determination and interpretation. In Techniques in Sedimentology (Edited by Tucker M.), pp. 63-85. Blackwell, Oxford.

Muller R. N. and Tisue G. T. (1977) Preparative-scale size fractionation of soils and sediments and an application to studies of plutonium geochemistry. Soil Sci. 124, 191-198.

Owen M.W. (1976) Determination of the settling velocities of cohesive muds. Report No. IT 161, Hydraulics Research Station, Wallingford, U.K.

Umlauf G. and Bierl R. (1987) Distribution of organic micropoliutants in different size fractions of sediment and suspended solid particles of the River Rotmain. Z. Wass. Abwass.-Forsch. 20, 203-209.

Vanoni V. A. (1975) Sedimentation Engineering. American Society of Civil Engineers, New York. 
Walling D. E. (1989) Physical and chemical properties of sediment: the quality dimension. Int. J. Sediment Res. 4, $27-39$.

Walling D. E. and Moorehead P. (1989) The particle size characteristics of fluvial suspended sediment: an overview. Hydrobiologia 176/177, 125149.
Woodward J. C and Walling D. E. (1992) A field sampling method to obtain representative samples of composite fluvial suspended sediment particles for SEM analysis. J. Sediment. Petrol. 64, 742-744.

Zabawa (1978) Microstructure of agglomerated suspended sediments in Chesapeake Bay estuary. Science 202, 49-51. 